\title{
Squamous cell carcinoma of the nipple following radiation therapy for ductal carcinoma in situ: a case report
}

\author{
Catherine E Loveland-Jones' ${ }^{1}$ Fengwei Wang22, Robin R Bankhead' ${ }^{1}$, Yajue Huang² and Kathleen J Reilly*1
}

\begin{abstract}
Introduction: Radiation-induced nonmelanoma skin cancer was first reported seven years after the discovery of Xrays, but has received relatively little consideration in the literature. Specifically, nonmelanoma skin cancer after conservative surgery and radiation for early stage breast cancer has not been well studied. We report the case of a woman who developed squamous cell carcinoma of the nipple nine years after conservative surgery and radiation for ductal carcinoma in situ of the ipsilateral breast. We also review the relevant literature available to date.
\end{abstract}

Case presentation: A 66-year-old African-American woman presented to the hospital with a non-healing ulcer of the right nipple. Her past medical history was significant for right breast ductal carcinoma in situ for which she had undergone lumpectomy and whole breast radiation therapy nine years previously. Mammography and magnetic resonance imaging studies were negative for recurrent breast cancer. However, the latter demonstrated abnormal enhancement in the nipple-areolar region. An incisional biopsy of the lesion demonstrated invasive squamous cell carcinoma. Subsequently, the patient underwent wide excision of the nipple-areolar complex. Sentinel lymph-node biopsy was offered but our patient declined. She was considered to have local disease and hence no further treatment was recommended.

Conclusion: This case represents the first reported occurrence of squamous cell carcinoma of the nipple to follow conservative surgery and radiation for ductal carcinoma in situ of the ipsilateral breast. It is likely that radiation overexposure resulted in a radiation burn and subsequent radiodermatitis, placing it at risk for squamous cell carcinoma. A diagnosis of squamous cell carcinoma should be considered in a patient with a nipple lesion following radiation therapy for breast cancer.

\section{Introduction}

Breast-conserving surgery followed by whole breast radiation is a common mode of treatment for breast cancer, and is equivalent to mastectomy in the treatment of early stage disease [1,2]. Radiation has no detrimental effects on breast cancer survival and, as recently reported, may actually increase survival when given optimally in accordance with modern dose and target recommendations [3]. Nevertheless, radiation has been reported in several studies to increase the risk of second non-breast malignancies, including leukemia, sarcoma, lung cancer, and esophageal cancer. In one report comparing breast cancer

* Correspondence: kathleen.reilly2@tuhs.temple.edu

1 Department of Surgery, Temple University Hospital, 3401 North Broad Street, Philadelphia, PA, 19140, USA

Full list of author information is available at the end of the article patients who received radiation therapy after surgery with those who did not, the relative risks of lung cancer and myeloid leukemia were 1.62 and 2.99 , respectively [4]. The development of these second malignancies is influenced by patient factors such as age, tobacco use, and history of adjuvant systemic therapy $[5,6]$.

Radiation-induced nonmelanoma skin cancer (NMSC) was first reported seven years after the discovery of Xrays [7]. Despite this long established relationship, NMSC is not consistently included in studies evaluating second non-breast malignancies that follow conservative surgery and radiation for breast cancer. We present the case of a woman who developed squamous cell carcinoma (SCC) of the nipple nine years after conservative surgery and radiation for ductal carcinoma in situ (DCIS) of the ipsilateral breast. 


\section{Case presentation}

In December 2007, a 66-year-old African-American woman with a past medical history significant for diabetes mellitus, hypertension, congestive heart failure, and fibroids presented to the Temple University Hospital, Philadelphia with a non-healing ulcer of the right nipple. The patient's past medical history was also significant for right breast DCIS for which she had undergone lumpectomy and whole breast radiation therapy in February 1998. These interventions were followed by five years of tamoxifen therapy. By mammography, the DCIS lesion measured three centimeters and was located six centimeters from the nipple in the inferomedial quadrant of the right breast. At lumpectomy, the lesion was a nuclear grade II/III micropapillary tumor with apocrine features (Figure 1). The margins of the specimen were negative for tumor.

Our patient received a standard course of radiation. Over 34 days, the right breast was treated with $6 \mathrm{Mv}$ photons to a dose of 5000 cGy using medial and lateral tangential fields measuring $16 \times 22 \mathrm{~cm}$. Fifteen degree wedges were used to enhance dosimetry. The daily fraction size was 200 cGy. Over four days, the area of resection was boosted an additional 1000 cGy using an en face $16 \mathrm{MeV}$ electron field measuring $12 \times 5 \mathrm{~cm}$. The total dose of radiation was 6000 cGy.

Nine years after surgery and radiation, our patient presented with a non-healing ulcer of the right nipple (Figure 2). The lesion was an irregularly shaped excoriation that partially eroded through the nipple. There was both serous and bloody discharge. The surrounding nippleareolar tissue was effaced, retracted, and indurated. There was no odor or cellulitis. She stated she had been suffering from a "raw" right nipple with intermittent healing for approximately two years.

There were no other significant physical exam findings, including no palpable axillary lymphadenopathy. Mammography and magnetic resonance imaging studies were

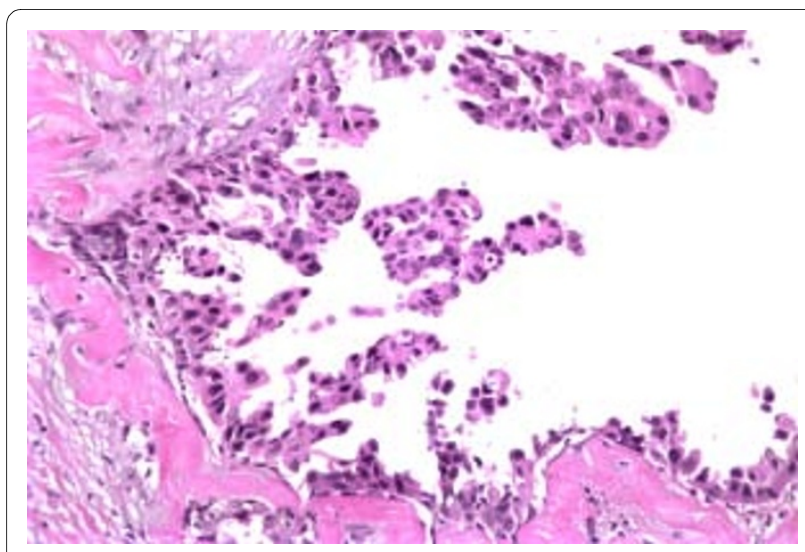

Figure 1 Right breast DCIS, micropapillary type

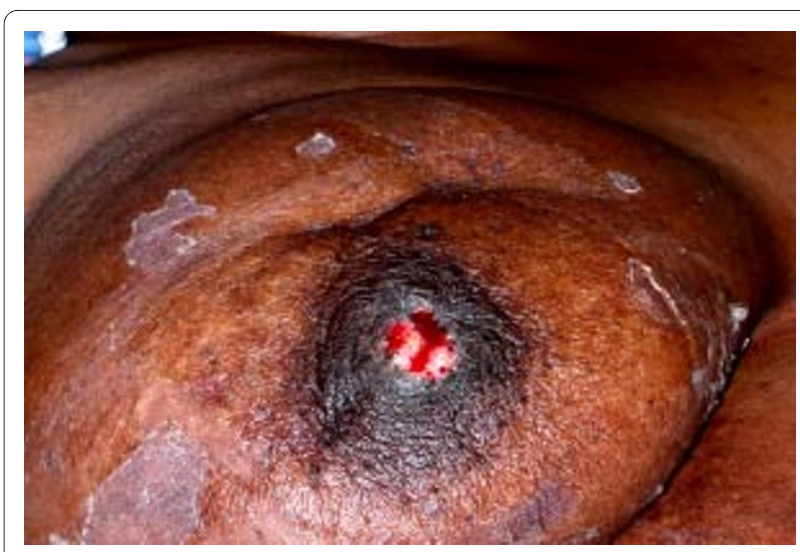

Figure 2 Gross depiction of nipple ulcer.

negative for recurrent breast cancer. However, the latter demonstrated abnormal enhancement in the nipple-areolar region.

An incisional biopsy of the lesion demonstrated invasive SCC. Subsequently, our patient underwent wide excision of the nipple-areolar complex. Pathologically, the lesion measured $15 \mathrm{~mm}$ (length) $\times 14 \mathrm{~mm}$ (width) $\times 9$ $\mathrm{mm}$ (depth) and was characterized as a moderately to poorly differentiated invasive SCC (Figure 3). Immunohistochemical staining was positive for CK903 (Figure 4), CK5/6, p63 (Figure 5), and calponin and negative for estrogen and progesterone receptors as well as Her-2/ neu, supporting a diagnosis of SCC. The resection margins were free of tumor and there was no evidence of lymphovascular invasion. The tumor was staged T1N0M0 (Stage 1).

Our patient was felt to be at high risk for recurrence according to the National Comprehensive Cancer Network Clinical Practice Guidelines [8]. Specifically, her tumor occurred at the site of prior radiation therapy and had poorly defined borders, a depth greater than $4 \mathrm{~mm}$,

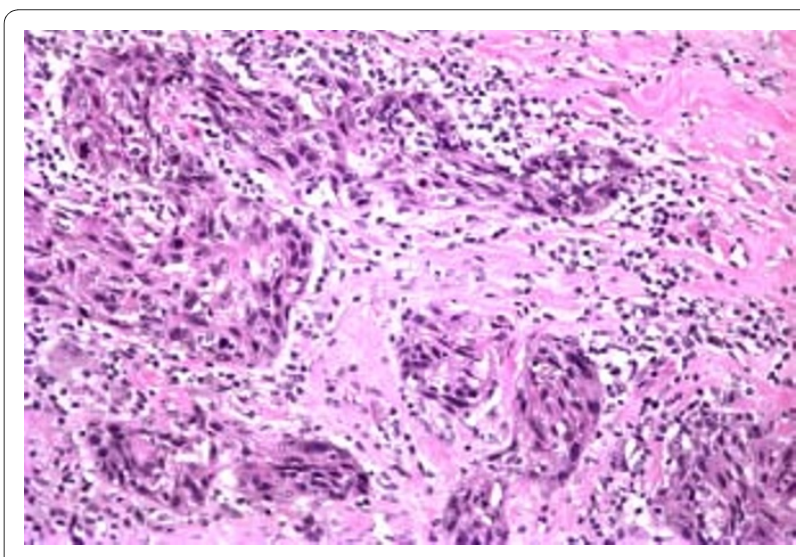

Figure 3 Right breast moderately to poorly differentiated invasive SCC 


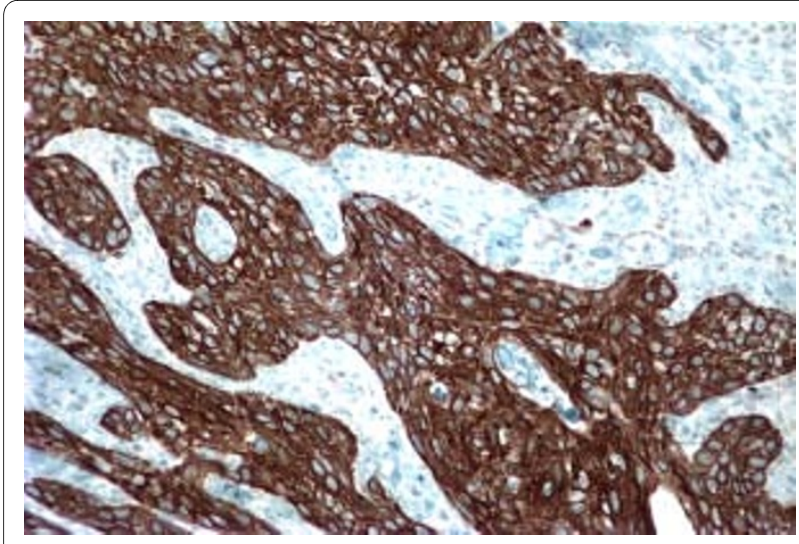

Figure 4 CK903 immunostaining of SCC.

and a moderate to poor differentiation. For this reason, re-excision of the area was performed to ensure minimum $10 \mathrm{~mm}$ margins were obtained. Sentinel lymphnode biopsy was offered but our patient declined.

She was considered to have local disease and hence no further treatment was recommended. She will have close clinical follow-up biannually and mammography annually. She was also instructed to perform self skin and lymph node exams.

\section{Discussion}

Multiple risk factors for SCC have been defined. The most significant of these is solar radiation exposure. Multiple studies have shown the incidence of SCC increases with proximity to the equator and cumulative sun exposure [9]. Others risk factors include fair coloring, genetic disorders of photosensitivity (e.g. xeroderma pigmentosum), chronic skin conditions (e.g. burn scars and venous ulcers), impaired immunity, and exposures (e.g. arsenic and radiation therapy).

Radiation therapy has also been described as a risk factor for SCC. In a report from the Childhood Cancer Sur-

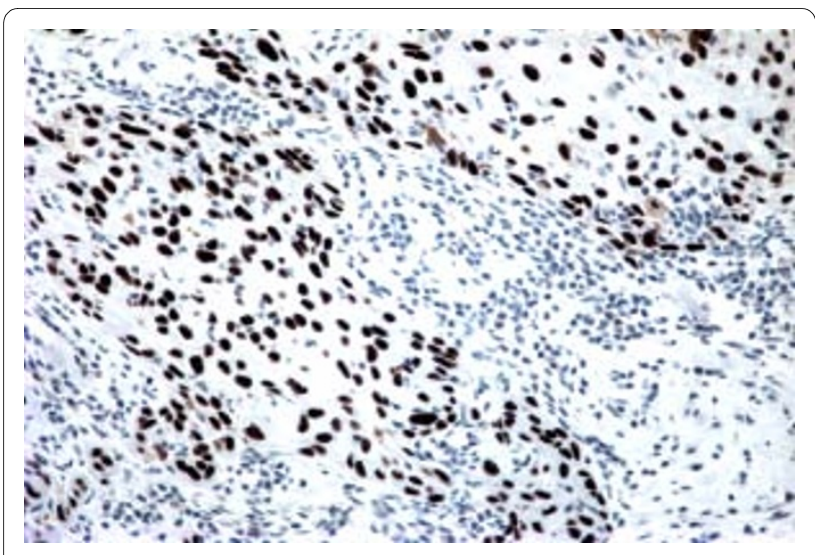

Figure 5 p63 immunostaining of SCC. vivor study, radiation therapy was associated with a 6.3 fold-increase in risk for NMSC (SCC and basal cell carcinoma). Of these cancers $90 \%$ occurred within the radiation field [10]. The association between radiation and NMSC is also prevalent in the head and neck literature.

SCC subsequent to radiation therapy appears to be more aggressive than that due to sunlight. In one study, SCC arising in previously burned or irradiated skin was associated with a five-year survival of only $52 \%$. This was in contrast to the $90 \%$ five-year survival observed in patients with sunlight-induced SCC. Proposed explanations of this difference included greater biologic aggressiveness of scar SCC, delayed presentation, and areas of scarring being immunologically privileged sites [11].

Despite an extensive literature search, no reports of SCC of the nipple following radiation therapy for breast carcinoma were found. This result is surprising given the large number of patients undergoing radiation therapy for breast cancer. Overall, SCC of the nipple is quite rare, likely because the area is not a sun-exposed region of the body.

Multiple technical factors during radiation therapy for breast cancer influence the risk of second malignancies. These include quality, total dose, fractionation, degree of overlap between the fields, tissue volume in the radiation field, as well as the degree and quality of scatter outside the radiation field $[6,12]$. The nipple is at significant risk for exposure to toxic doses of radiation if it protrudes into the radiation field unshielded by other tissue. In effect, it may become a "hotspot". Furthermore, inconsistent positioning of the nipple places it at further risk for radiation overexposure. Our patient has large, pendulous breasts, making inconsistent positioning more likely. Exposure of the normal nipple tissue to high doses of radiation may result in radiodermatitis, a risk factor for SCC. Fortunately, improvements in radiation technique over the last decade have decreased the risk of overexposure to the nipple and acute radiation skin toxicity [13].

It is important to keep in mind that the absolute risk of death from a second malignancy following radiation therapy for breast cancer is less than 1\% per year [6]. This risk is much smaller than the survival benefit derived from radiation therapy, which is about $6 \%$ at ten years [3].

SCC of the nipple should be included in the differential diagnosis of a nipple lesion in a patient presenting after radiation therapy. Other diagnoses to consider include basal cell carcinoma, recurrent breast cancer, Paget's disease, and radiodermatitis.

Treatment options for SCC depend on the risk of recurrence and the presence of positive lymph nodes. Risk factors for recurrence include large diameter $(\geq 20 \mathrm{~mm}$ on the trunk and extremities, $\geq 10 \mathrm{~mm}$ on the cheeks, forehead, scalp, and neck, or $\geq 6 \mathrm{~mm}$ on the face, genitalia, hands, and feet) poorly-defined borders, recurrence, 
immunosuppression, occurrence at the site of prior radiation therapy or chronic inflammation, rapid growth, neurologic symptoms, moderate or poor differentiation, adenoid/adenosquamous/desmoplastic subtypes, greater depth (Clark levels level IV/V or $\geq 4 \mathrm{~mm}$ ), and perineural or vascular involvement [8].

Patients without any of these risk factors are at low risk for recurrence and may be treated with field therapies such as curettage and electrodessication. Otherwise, both low and high risk patients are treated surgically with assessment of margins. Surgical options include standard excision with post-operative margin assessment or Mohs micrographic excision using frozen section. Margin adequacy depends on recurrence risk status, size, and location but generally falls between $4 \mathrm{~mm}$ and $10 \mathrm{~mm}$. Patients with positive lymph nodes, positive margins after surgery, extensive nerve involvement, and those who are not surgical candidates should be treated with radiation therapy [8].

\section{Conclusions}

This case represents the first reported occurrence of SCC of the nipple to follow conservative surgery and radiation for DCIS of the ipsilateral breast. It is likely that radiation overexposure resulted in a radiation burn and subsequent radiodermatitis, placing it at risk for SCC. A diagnosis of SCC should be considered in a patient with a nipple lesion following radiation therapy for breast cancer.

\section{Consent}

Written informed consent was obtained from the patient for publication of this case report and any accompanying images. A copy of the written consent is available for review by the journal's Editor in Chief.

\footnotetext{
Abbreviations

DCIS: ductal carcinoma in situ; NMSC: nonmelanoma skin cancer; SCC: squamous cell carcinoma.
}

\section{Competing interests}

The authors declare that they have no competing interests.

\section{Authors' contributions}

$C L J$ reviewed the literature and wrote the manuscript. KJR carried out the operation on the patient and was the primary editor of the manuscript. RRB assisted in the care of the patient and edited the manuscript. FW and $\mathrm{YH}$ provided the pathology images and interpretation. All authors read and approved the final manuscript.

\section{Author Details}

'Department of Surgery, Temple University Hospital, 3401 North Broad Street, Philadelphia, PA, 19140, USA and 2Department of Pathology, Temple University Hospital, 3401 North Broad Street, Philadelphia, PA, 19140, USA

Received: 22 October 2009 Accepted: 21 June 2010

Published: 21 June 2010

\section{References}

1. Arriagada R, Le MG, Rochard F, Contesso G: Conservative treatment versus mastectomy in early breast cancer: patterns of failure with 15 years of follow-up data. J Clin Oncol 1996, 14:1558-64.

2. Veronesi U, Cascinelli N, Mariani L, Greco M, Saccozzi R, Luini A, Aquilar M, Marubini E: Twenty-year follow-up of a randomized study comparing breast-conserving surgery with radical mastectomy for early breast cancer. N Engl J Med 2002, 347:1227-32.

3. Gebski V, Lagleva M, Keech A, Simes J, Langlands AO: Survival effects of postmastectomy adjuvant radiation therapy using biologically equivalent doses: a clinical perspective. J Natl Cancer Inst 2006, 98:26-38.

4. Roychoudhuri R, Evans H, Robinson D, Moller H: Radiation-induced malignancies following radiotherapy for breast cancer. $\mathrm{Br} J$ Cancer 2004, 91(5):868-72.

5. Fowble B, Hanlon A, Freedman G, Nicolaou N, Anderson P: Second cancers after conservative surgery and radiation for stages I-II breast cancer: identifying a subset of women at increased risk. Int J Radiat Oncol Biol Phys 2001, 51:679-90.

6. Neugut Al, Weinberg MD, Ahsan H, Rescigno J: Carcinogenic effects of radiotherapy for breast cancer. Oncology 1999, 13:1245-52.

7. Frieben A: Demonstration eines cancroids des rechten handruckens, das sich nach langedauernder einwirkung von rontgenstrahlen entwickelt hatte. Fortschr Rontgestr 1902, 6:106-11.

8. National Comprehensive Cancer Network Clinical Practice Guidelines in Oncology. Basal Cell and Squamous Cell Skin Cancers. V.1.2008 [http://www.nccn.org/professionals/physician gls/PDF/nmsc.pdf

9. Goldman GD: Squamous cell cancer: a practical approach. Semin Cutan Med Surg 1998, 17:80-95.

10. Perkins JL, Liu Y, Mitby PA, Neglia JP, Hammond S, Stovall M, Meadows AT, Hutchinson R, Dreyer ZE, Robison LL, Mertens AC: Nonmelanoma skin cancer in survivors of childhood and adolescent cancer: a report from the childhood cancer survivor study. J Clin Oncol 2005, 23:3733-3741.

11. Edwards MJ, Hirsch RM, Broadwater JR, Netscher DT, Ames FC: Squamous cell carcinoma arising in previously burned or irradiated skin. Arch Surg 1989, 124:115-117.

12. Pierce SM, Recht A, Lingos TI, Abner A, Vicini F, Silver B, Herzog A, Harris JR: Long-term radiation complications following conservative surgery and radiation therapy in patients with early stage breast cancer. Int J Radiat Oncol Biol Phys 1992, 23:1085-1086.

13. Pignol JP, Olivotto I, Rakovitch E, Gardner S, Sixel K, Beckham W, Vu TT, Truong P, Ackerman I, Paszat L: A multicenter randomized trial of breast intensity-modulated radiation therapy to reduce acute radiation dermatitis. J Clin Oncol 2008, 26:2085-2092.

doi: 10.1186/1752-1947-4-186

Cite this article as: Loveland-Jones et al., Squamous cell carcinoma of the nipple following radiation therapy for ductal carcinoma in situ: a case report Journal of Medical Case Reports 2010, 4:186

\section{Submit your next manuscript to BioMed Centra} and take full advantage of:

- Convenient online submission

- Thorough peer review

- No space constraints or color figure charges

- Immediate publication on acceptance

- Inclusion in PubMed, CAS, Scopus and Google Scholar

- Research which is freely available for redistribution

Submit your manuscript at www.biomedcentral.com/submit
C Biomed Central 